\title{
MANOEL BomfiM: DEBATES PARLAMENTARES SOBRE ESTADO E INSTRUÇÃO PRIMÁRIA NA PRIMEIRA DÉCADA DO SÉCULO XX
}

\author{
LIGIANE APARECIDA dA Silva \\ Maria Cristina Gomes Machado \\ Universidade Estadual de Maringá (UEM), Maringá, Paraná, Brasil
}

\begin{abstract}
Resumo: Este trabalho apresenta uma investigação do posicionamento do intelectual Manoel Bomfim (1868-1932) frente ao debate sobre a relação Estado e instrução primária nos discursos parlamentares proferidos entre os anos de 1907 e 1908, atualmente disponíveis na coletânea Documentos Parlamentares: Instrução Pública, publicada em 1918 pelo Jornal do Comércio. A posição assumida por esse intelectual ocorre num contexto caracterizado por tentativas de organização do trabalho livre, estruturação da República, preparo do povo para o exercício da cidadania e surgimento de demandas sociais que exigiram investimento na instrução popular. Manoel Bomfim mostra-se comprometido com o desenvolvimento e difusão da instrução primária e envolvido no movimento em prol da escolarização da classe trabalhadora.
\end{abstract}

Palavras-chave: História da Educação. Estado e instrução primária. Primeira República. Manoel Bomfim.

\section{CONSIDERAÇÕES INICIAIS}

O período intitulado de Primeira República no Brasil abarca os anos finais do século XIX e as três primeiras décadas do século XX. Trata-se de um momento histórico marcado por debates e iniciativas de intelectuais e par- 
lamentares com vistas à estruturação da República e atenção às demandas que lhe são inerentes.

No presente artigo pretendemos contribuir para a reflexão acerca do Projeto Tavares Lyra e discorrer sobre a centralidade que a instrução primária assume na discussão dos personagens em cena. Privilegiamos o intelectual Manoel José do Bomfim (1868-1932) e os discursos que proferiu enquanto deputado federal pelo estado de Sergipe quando da tramitação do referido projeto, ocorrida de 24 de junho de 1907 a 23 de novembro de 1908.

Elaborado por uma Comissão de Instrução 1 a partir das diretrizes apresentadas pelo então Ministro de Estado da Justiça e Negócios Interiores do Brasil, Augusto Tavares de Lyra (1872-1958), o Projeto Tavares Lyra tinha por objetivo promover uma reforma no ensino secundário e superior, bem como o desenvolvimento e a difusão da instrução primária.

Em relação à instrução primária, projetava-se a intervenção direta e imediata da União por meio de acordo com os estados e municípios. Alegava a Comissão que da escolarização das massas dependia o progresso do país e sua inserção na disputa econômica com os países industrializados. No entanto, esbarrava na Constituição Federal de 1891 que atribuíra aos estados e municípios a responsabilidade pela manutenção e investimento nas escolas primárias².

Manoel Bomfim mostrou-se favorável à proposta ${ }^{3}$. Em seu discurso, proferiu elogios à iniciativa do Ministro Tavares de Lyra, apresentou sugestões e emendas e buscou explicitar aos parlamentares seu entendimento acerca da função social do ensino primário, do ensino secundário e do ensino superior e os motivos que o levavam a privilegiar a escolarização elementar.

Sua inserção nesse debate, a nosso ver, deve ser compreendida como expressão de um momento histórico caracterizado pela necessidade de se estruturar o novo regime, organizar o trabalho livre, acelerar o desenvolvimento da indústria e do comércio e preparar o povo para o exercício do voto, para o trabalho especializado, para a defesa da pátria e desafios próprios da vida urbana. São as transformações concretas da sociedade brasileira sucedidas no período em tela que permitem, portanto, o estudo do pensamento desse 
autor se considerarmos a própria história como fundamento de suas ideias. (MARX, 1982).

Por ter sido um intelectual diretamente envolvido com os dilemas de sua época e por ter produzido uma vasta obra na qual atribui relevância à instrução popular, Manoel Bomfim merece atenção dos que buscam compreender o processo histórico de luta pela consolidação da escola pública brasileira. Sua participação nas discussões referentes ao Projeto Tavares Lyra, em especial, é fonte profícua por apresentar o posicionamento político do autor frente ao histórico debate sobre a relação escola primária e progresso nacional.

Este texto discute as questões apresentadas de modo a abordar: 1) vida, formação e vínculo de Manoel Bomfim com as mudanças ocorridas no limiar da República e 2) o papel que atribuiu ao Estado em relação à instrução primária e seu posicionamento ante o Projeto Tavares Lyra. Por fim, tecemos nossas considerações finais, alegando que a necessidade de escolarizar as massas não representou, naquele momento, uma questão de segurança nacional, o que possivelmente contribuiu para a não aprovação do Projeto e das sugestões apresentadas por Manoel Bomfim e seus pares.

\section{Manoel Bomfim em SeU TeMPo}

A historiografia brasileira dedicada ao estudo da obra de Manoel Bomfim tem adjetivado este autor de nacionalista apaixonado (LEITE, 1983), inovador ambíguo (SUSSEKIND; VENTURA, 1984), republicano radical (SILVA, 1990), revolucionário e eminente pensador da América Latina (SOUTO MAIOR, 1993), rebelde e portador de um contradiscurso (AGUIAR, 2000), leitor da história a contrapelo (REIS, 2006), representante da ética burguesa (BORGES, 2006), intelectual polígrafo e pensador da história (GONTIJO, 2010), ensaísta intencionalmente silenciado (ALVES FILHO, 2013), para citar apenas alguns de seus intérpretes.

As divergências entre as adjetivações são compreensíveis se considerarmos que a obra de um intelectual, por ser construída a partir de uma realidade complexa e contraditória, expressa as especificidades do momento 
em que foi engendrada, como certifica Machado (2014). Para esta autora, o engajamento de um intelectual na defesa de determinada classe está sujeito a questões políticas e institucionais que delimitam os espaços e os limites de sua atuação. A obra de Manoel Bomfim, portanto, bem como seu vínculo parlamentar, articula-se com as transformações políticas, econômicas, culturais e sociais ocorridas no alvorecer da República. Logo, "[...] o lugar de onde fala, para quem fala e a serviço de quem está, é a espinha dorsal para a compreensão das ideias, ações, projetos e engajamento de um intelectual. (MACHADO, 2014, p. 96-97).

Manoel Bomfim morreu em 21 de abril de 1932 e deixou um importante legado para a história da educação brasileira ainda pouco explorado em nossos programas de pós-graduação em educação. Foi médico de formação, mas estudou psicologia em Paris como aluno de Alfred Binet, foi professor da Escola Normal, diretor do Pedagogium, diretor do primeiro laboratório de Psicologia Experimental do país (do qual foi fundador), jornalista, secretário da educação do Rio de Janeiro, deputado federal por Sergipe, criador de revistas educacionais para o público adulto e infantil, redator em periódicos, membro da Liga Brasileira de Higiene Mental, autor de livros sobre história do Brasil e da América Latina, além de livros didáticos e paradidáticos, alguns produzidos em parceria com Olavo Bilac e oficialmente adotados por estados brasileiros para uso nas escolas públicas por alunos e professores 4 .

Nascido em Aracaju no dia 8 de agosto de 1968, viveu entre o Império e a República, entre o mundo rural e o espaço urbano e seus 68 anos de vida estão divididos exatamente da seguinte forma: 32 anos no século XIX e mais 32 no século XX, como bem observou Reis (2006). Esse detalhe aparentemente irrelevante contribui para a compreensão da leitura que fez da sociedade brasileira em vias de transição.

Bomfim era filho do comerciante e dono de engenho Paulino José do Bomfim. Por optar pela Medicina, mudou-se em 1886 para Salvador para realizar seus estudos na Faculdade de Medicina da Bahia e, posteriormente, para o Rio de Janeiro, onde desenvolveu grande parte de sua atividade intelectual e política. Observou a escravidão e presenciou a transição de regime aos 21 anos de idade, já quase formado e, portanto, com certa maturidade 
para refletir sobre os rumos que trilhava seu país. Assistiu à fundação de uma República que, em sua opinião, fora estrategicamente organizada para a manutenção dos conservadores no poder. (BOMFIM, 1996; 1997; 2008; 2013)5.

É a partir de 1896 que o intelectual aludido passa a se envolver de forma mais próxima com a educação, por meio de nomeação ao cargo de subdiretor do Pedagogium e pelo fato de ter assumido a redação e a secretaria do periódico A República. Contudo, é no ano de 1897 que seu vínculo com a educação se acirra. Bomfim assume a direção geral do Pedagogium, a redação e secretaria do mensário Educação e Ensino e publica um artigo no periódico A República, em que declara seu genuíno interesse pela instrução pública brasileira. Este seu texto é citado e lido dez anos depois para os parlamentares na discussão do Projeto Tavares Lyra, que doravante denominaremos de Projeto.

Manoel Bomfim foi um crítico da política de seu tempo. Em A América Latina: males de origem, livro publicado pela primeira vez em 1905, faz uma retrospectiva histórica do processo de colonização do Brasil e das nações latino-americanas e conclui que o sistema político parasita das metrópoles se consolidara e se reproduzia entre os políticos conservadores da República, entravando o desenvolvimento do Brasil. Rejeita a visão disseminada na Europa e Estados Unidos acerca da América Latina que, segundo ele, era distorcida e tendenciosa, apresentando-nos como incivilizados, inferiores e ignorando as particularidades de cada nação desse continente.

Esse estado de espírito, esse modo de ver mantém-se também pela absoluta ignorância dos publicistas e sociólogos europeus sobre a América Latina. Pode-se dizer que essa condenação tem uma dupla causa: a causa afetiva, interesseira; e uma causa intelectual - a inteira ignorância das nossas condições e da nossa história social e política, no passado e no presente. Esta é uma verdade que se reflete em cada conceito com que se nos acabrunham. (BOMFIM, 2008, p. 6).

Em O Brasil na América: caracterização da formação brasileira, passados 24 anos, Bomfim desenvolverá com mais profundidade os principais conceitos de A América Latina, buscando evidenciar as especificidades do Brasil em relação aos países ibero-americanos. Cabe destacar a polêmica travada com Sílvio Romero (1851-1914) em torno das ideias defendidas por Bomfim, que rejeitava a tese da desigualdade das raças humanas disseminada desde $\circ$ 
século XIX pelo influente escritor e filósofo francês Joseph Arthur de Gobineau. Para Bomfim, o atraso brasileiro era de ordem cultural e é nesse sentido que a instrução popular assume importância em seu projeto de nação como critério para a modernização almejada.

A obra de Bomfim é permeada de exaltações ao povo brasileiro por sua coragem, brandura, afetuosidade e riqueza cultural proveniente do encontro entre diferentes tradições que dialogavam e se transformavam com o passar do tempo (BOMFIM, 1997; 2000). O autor defendia a possibilidade de aprendizagem dos negros, índios e mestiços, desde que houvesse o investimento necessário em instrução elementar.

Bomfim é considerado romântico e ingênuo por alguns estudiosos de sua obra (REIS, 2006; ANDRADE, 2008), mas entendemos que seu discurso deve ser analisado enquanto prática e não como mero palavreado alijado da realidade da Primeira República. Os termos carregados de emoção que utilizou, a nosso ver e conforme as reflexões de Marta Maria Chagas de Carvalho (1989) fazem parte de um conjunto de estratégias e objetos de intervenção comumente utilizados na época para ampliar os espaços de atuação e persuadir povo e elite. $O$ presente é apresentado de forma temerosa como momento de insegurança e incertezas, mas prenhe de possibilidades; o futuro, como época promissora caso o projeto de nação apresentado fosse levado a termo; o passado é exposto como sinônimo de atraso e obsolescência.

Os discursos republicanos de apologia ao restabelecimento moral e intelectual da sociedade incitavam o debate sobre a necessidade de investimentos na instrução primária, formadora por excelência das novas gerações de cidadãos almejados. Bomfim dedicou-se com afinco a essa causa nas várias frentes em que atuou e a defesa da escolarização das massas está presente, direta ou indiretamente, em praticamente toda a sua obra.

José Murilo de Carvalho (1990), ao estudar o imaginário da República no Brasil a partir do mapeamento das correntes ideológicas mais influentes nas primeiras décadas do novo regime, apresenta as utopias dos projetos societários da época e os instrumentos utilizados para envolver a massa não escolarizada na vida política. $\mathrm{O}$ autor mencionado discorre sobre os mitos, alegorias, imagens e símbolos que contribuíram para a elaboração desse 
imaginário e "[...] redefinição de identidades coletivas" (CARVALHO, 1990, p. 11). Há que se considerar que Bomfim, como um homem de seu tempo e defensor de um projeto de nação, nascido do compartilhamento de ideias entre sujeitos históricos e grupos políticos, tenha se utilizado das mesmas ferramentas para apoderar-se do imaginário popular e convencer seus opositores. $\mathrm{O}$ uso de adjetivos e metáforas e de termos próprios da biologia e da medicina para explicar questões sociais pode ser entendido como tentativas de se fazer entender, de cientificizar suas ideias para credibilizar o discurso, sustentado por uma visão de homem, de história e de República.

A utilização dos termos "progresso", "moderno", "científico", "novo" e até "revolução" é recorrente no Brasil, sobretudo a partir das últimas décadas do século XIX, como pontuam Herschmann e Pereira (1994). Na perspectiva desses autores, o modelo europeu de civilização incitava intelectuais brasileiros ao confronto com as estruturas historicamente estabelecidas porque de sua derrocada dependia a inserção do Brasil no mercado internacional de forma competitiva.

Em contrapartida, a despeito do discurso inflamado de apologia à ciência e da repulsa à tradição, a modernização brasileira se materializou de forma conservadora por meio de reformas educacionais e políticas de cunho médico-higienista tendo como definidor de regras o“[...] projeto civilizatório ocidental", como destacou Gondra (2004, p. 482).

Bomfim, como médico, professor, escritor e parlamentar, participou ativamente dessa querela entre "obsoletos" e "modernos" e do processo de criação das condições necessárias à consolidação da República. Embora tenha abdicado do exercício direto da medicina em 1894, sua formação o acompanhou na prática da docência, nos textos recheados de metáforas, nas comparações que fez entre os organismos sociais e os organismos biológicos,

Seus escritos históricos têm como característica comum o esforço que empenhou para recuperar o passado que autorizara o Brasil em que vivia. É importante, contudo, compreender que Bomfim se utilizava de analogias, mas não de forma acrítica. Alertava seus leitores para as diferenças entre as leis que regiam a natureza e as leis sociais, mais complexas em sua essência, segundo ele. (BOMFIM, 2008). 
Sussekind e Ventura (1984) concluíram que a obra de Bomfim não ganhou visibilidade no percurso do século XX porque, dentre outros fatores, a linguagem por ele utilizada estava em vias de superação. De fato estava como ele mesmo afirmou: "Está um tanto desacreditado, em sociologia, esse velo de assimilar, em tudo e para tudo, as sociedades aos organismos biológicos". Entretanto, alertou:“[...] não é o conceito que é condenável, e sim a estreiteza de vista com que o aplicam à crítica dos fatos sociais [...]". (BOMFIM, 2008, p. 17). Não se tratava, portanto, de mera comparação, mas de acreditar na existência de leis regentes da vida em sociedade de essência similar às leis que regem a natureza.

A partir dessa crença é que o referido intelectual cria a categoria imprescindível para a apreensão de seu pensamento, qual seja, o parasitismo social. Utilizando como exemplo o processo de evolução de um pequeno animal marinho que se tornou parasita - o Chondracantus gibbosus -, o autor esclarece ao leitor que a exploração social degenera tanto o"parasita" quanto o "parasitado", na medida em que ambos têm as suas possibilidades de desenvolvimento reduzidas.

O parasitado adoece, pois tem sua energia e saúde subtraídas; o parasita tem a ilusão da vantagem, mas regride enquanto organismo vivo. $O$ parasita histórico - Portugal, que deixou heranças culturais para a República - e o novo parasita, a elite conservadora dos tempos de Bomfim - causava a doença: um povo ignorante e esmorecido, uma economia desequilibrada, recursos mal investidos ou desviados, desemprego, instabilidade social, falta de mão-de-obra especializada, escassez de políticas públicas em prol da modernização. $O$ tratamento: a formação de um povo consciente e preparado para a vida na República; a cura: destituição do parasita e consequente recuperação da saúde do corpo social.

Uma solução superestrutural inspirada na medicina e na psicologia, como destacou Reis (2006). Bomfim, como médico apresenta a cura para os males da nação e, como psicólogo, se propõe a tratar da autoestima do brasileiro negativamente afetada pela tese da inferioridade dos latino-americanos.

As questões até aqui pontuadas aparecerão, implícita ou explicitamente, em sua exposição aos parlamentares proferida no ano de 1907. 
Bomfim, em consonância com a Comissão de Instrução e outros parlamentares favoráveis ao Projeto, declarará publicamente sua opinião em relação ao dever do Estado para com a instrução primária e formação das classes populares, como apresentaremos a seguir.

\section{O PRojeto E SUA QUESTÃo CAPITAL}

No dia 5 de novembro de 1907 Manoel Bomfim ocupa a tribuna da Câmara dos Deputados ${ }^{6}$, seguido dos parlamentares Graccho Cardoso, Graciano Neves e Passos de Miranda. Sua exposição tem início com a seguinte consideração: o projeto contemplava duas questões distintas que poderiam ser tratadas separadamente com a atenção apropriada.

A proposta para o desenvolvimento e difusão da instrução primária foi por ele considerada questão capital por envolver a necessidade de um acordo entre União, estados e municípios e pela emergência do assunto em pauta. A segunda questão - reforma, reorganização e remodelação dos programas do ensino secundário e superior -, por seu caráter didático-pedagógico assumia importância secundária, cabendo aos parlamentares discuti-la posteriormente.

Bomfim se propõe a priorizar a questão de importância capital e justifica: “[...] é que justamente essa questão da instrução popular me tem parecido sempre, a mais interessante, aquela que mais influi ou deve influir sobre o destino do Brasil, e dela me tenho ocupado, constantemente" (BOMFIM apud BRASIL, 1918, p. 397).

Como se pode observar, Bomfim pertencia ao grupo de intelectuais que manifestava acentuado "entusiasmo" pela educação, para utilizar a expressão cunhada por Jorge Nagle (1974). Contemporâneo de personalidades como Rui Barbosa, Machado de Assis, José Veríssimo, Monteiro Lobato, Olavo Bilac, Carneiro Leão, Anísio Teixeira, Fernando de Azevedo, Lourenço Filho e outros influentes pensadores, escritores e políticos da República, não se furtou à reflexão sobre o conjecturado atraso brasileiro e as possíveis chaves para o almejado progresso. 
Ainda conforme Nagle (1974), mas sem considerar uma possível cisão temporal entre os entusiastas e otimistas da educação, é importante destacar que Bomfim deu continuidade a propostas presentes na trajetória de intelectuais e educadores do século XIX. Além de defender a instrução primária como alavanca para o desenvolvimento, propôs mudanças significativas nos métodos de ensino e na formação de professores, ambas afinadas com o ideário da pedagogia autoproclamada moderna e científica. Nos compêndios que produziu para uso nas Escolas Normais, nos livros de leitura e discursos proferidos sobre o magistério e a infância ${ }^{8}$, fica evidente a centralidade atribuída à criança no processo de ensino e aprendizagem, um debate pedagógico e, sobretudo, político que ganhou destaque entre os intelectuais brasileiros das primeiras décadas do século XX.

Recorremos novamente à Marta Carvalho (1989) para destacar que a escola primária foi reputada como responsável pela massa ignorante, doentia, pobre e indolente. $\mathrm{O}$ êxodo rural, atesta a autora, gerava desemprego nas cidades e falta de mão-de-obra no campo; a classe operária passa a ser vista como degenerada e os imigrantes europeus, como ameaçadores devido à influência das ideias de caráter socialista e anarquista provenientes dos países industrializados. A elite agrária, por sua vez, era tida como fútil e pouco operosa. Perante esse cenário, intelectuais do período passam a defender uma escola produtiva ajustada ao modelo fabril no intuito de reformar moral e intelectualmente a sociedade. A construção de prédios suntuosos, iniciada a partir de 1870 pelo Estado Imperial, a mudança nos métodos de ensino, bem como a ênfase na formação de professores, são iniciativas que visavam promover a homogeneidade ideológica via escola, atenuar conflitos e viabilizar o desenvolvimento nacional.

Na Câmara dos Deputados tais ideias vão aparecer com recorrência na fala dos parlamentares, mas a discussão que prevalece durante a tramitação do Projeto é a relação entre Estado e instrução popular. Bomfim explicita aos seus pares o seu posicionamento:

O problema da instrução popular, numa democracia, é por demais importante para que, hoje, ainda se possa com sensatez negar ao Estado o dever de intervir nele. Por minha parte, direi, mesmo que isto constitui uma das 
funções primordiais e explícitas do Estado moderno. (BOMFIM apud BRASIL, 1918, p. 401).

As controvérsias entre deputados pautavam-se na Constituição Federal de 1891. Era preciso debater e definir as competências da União nas questões afetas ao ensino de modo a não ferir a autonomia dos estados e municípios. Um Estado liberal, como destaca Chaves (2007), tem como premissa a garantia da liberdade dos indivíduos, assegurada pelo direito de não serem coagidos a nada, tampouco impedidos em sua livre iniciativa.

O autor supracitado acrescenta que a luta pela sobrevivência e pela melhoria das condições de vida na perspectiva do liberalismo é individual, cabendo ao Estado apenas a proteção do povo e defesa da soberania da nação. Bomfim utiliza-se desse pressuposto para contra-argumentar, sugerindo intervenção e investimentos na escolarização das crianças.

É inegável que cabe ao Estado a função de proteger aos fracos; está mesmo estabelecido de modo irrefutável que as funções primordiais do Estado são as de defesa da Nação contra os inimigos externos, e a defesa dos fracos ou a distribuição da justiça, no interior. Ora, quem mais fraco do que a criança?... Pois não é defendê-la - o arrancá-la a ignorância?... (BOMFIM apud BRASIL, 1918, p. 402).

Em Lições de Pedagogia: teoria e prática da educação, livro publicado por Bomfim pela primeira vez em 1915 reunindo conteúdos ensinados às alunas da Escola Normal durante o seu percurso como professor da cadeira de Pedagogia, a mesma ideia de criança como um ser a ser protegido aparece. Bomfim (1926, p. 12) defende que"[...] a educação é a adaptação do indivíduo às condições de vida humana" e a define como uma arte distinta porque

[...] aplica-se a um ser de natureza muito especial, - que é a personalidade humana, em formação. É uma arte que não trabalha com a simples matéria bruta, nem se dirige a organizações já constituídas. A entidade a que se aplica a educação não existe quase, nem está caracterizada, quando a obra educativa começa; é uma individualidade que se deve formar como resultado da própria educação. (BOMFIM, 1926, p. 10).

Portanto, delegar aos pais a escolha quanto à escolarização dos filhos e os investimentos necessários era visto por Bomfim como uma imprudência. 
Quem garantiria que o pai analfabeto, agricultor, operário ou até mesmo desempregado teria discernimento e condições materiais para intervir na educação dos filhos? Nesses casos, a "opção" por manter a criança distante da escola seria um exemplo adequado de exercício da liberdade? Ao condenar a criança ao analfabetismo não estariam os pais ferindo o princípio da dignidade humana prevista em lei? E quanto ao Estado, ao furtar-se do problema da instrução, não estaria abdicando de seu dever de proteger os cidadãos?

Bomfim, enquanto favorável ao projeto e à ideia da intervenção, retoma o histórico debate sobre a obrigatoriedade do ensino em busca de argumentos para problematizar os discursos oponentes e demonstrar que a proposta não confrontava a Constituição Federal; ao contrário, respeitava as suas máximas. Apresenta a função social da escola primária, instituição que considerava eminentemente educativa e cujo fim seria a adaptação da criança ao meio a partir do ensino de determinados conteúdos e valores. Vejamos:

Que é que o indivíduo deve aprender na escola primária? Tudo o que lhe é necessário para o desenvolvimento de suas relações, no meio dentro do qual temos de viver. Por isto, o ensino primário elementar se resume em aprender a ler, escrever e contar, conhecimento do sistema de pesos e medidas, e da instrução moral e cívica, pois estas são as noções essenciais a toda pessoa, qualquer que seja seu destino e a sua missão futura, da mais humilde à mais elevada. (BOMFIM apud BRASIL, 1918, p. 401).

O remédio se fazia necessário porque havia a enfermidade, mas o fim almejado era a cura e não a administração do remédio em si mesma. Educação popular financiada pelo Estado e revolução nacionalista, em nosso entendimento, não constituíam o projeto societário de Bomfim, mas o meio estratégico para se atingir o fim desejado, a saber, a modernização do país via industrialização. Na perspectiva de Botelho (2009), mesmo quando Bomfim propõe uma revolução nacionalista popular em O Brasil Nação e a destituição dos dirigentes políticos, tem como horizonte a educação do povo no pós-revolução e, então, a modernização da sociedade. Em outras palavras, a educação continuaria sendo o remédio para a cura dos nossos males. A escolarização das massas é o fio condutor que unifica e atribui identidade à sua obra e ao seu projeto. 
José Maria de Oliveira e Silva (1990) que, assim como Ronaldo Conde Aguiar (2000), investigou a participação de Bomfim nas discussões relacionadas ao Projeto identifica que a disseminação da instrução primária não se impunha como necessidade naquele momento, o que teria dificultado a aprovação do Projeto pelo parlamento. Na perspectiva de Aguiar (2000), o maciço investimento em instrução primária e a superação do analfabetismo não interessavam à influente elite agrária da Primeira República.

Para invocar o Estado e ratificar a proposta do Projeto, Bomfim exaltou o Brasil e o brasileiro. Frente ao paradigma que atestava a inferioridade da população latino-americana, alegou ser o atraso de ordem cultural e, por isso mesmo, passível de ser solucionado via instrução. Para tanto, chamou a atenção para a necessidade de investimentos na formação dos professores, propondo reestruturação e criação de Escolas Normais.

Para solução do problema da organização do ensino primário, que não está organizado, tem mais importância que a própria fundação e manutenção das escolas primárias, a organização das escolas normais. Não há ensino sem professores, a alma do ensino é o mestre. Fora absurdo esperar e acreditar na eficácia de um serviço de instrução com um professorado que não estivesse devidamente educado e preparado para isto. (BOMFIM apud BRASIL, 1918, p. 416).

Rosa Fátima de Souza (2004) ressalta que a Escola Normal foi central nas propostas de reforma de intelectuais e políticos no percurso do século XIX e nas primeiras décadas do século XX. Na República, em especial, o professor primário, enquanto responsável pela formação do contingente que iria por em movimento o projeto moderno de nação, deveria receber o preparo adequado em acordo com a pedagogia científica adotada nos países potencialmente industrializados.

Para finalizar sua exposição, Bomfim propõe três emendas ao Projeto e as justifica perante os deputados. A primeira delas estipulava que a União fundasse escolas primárias nos estados em locais onde elas não existissem e onde fossem insuficientes; a segunda criava a obrigatoriedade da criação de Escolas Normais federais pela União e a terceira determinava que a União auxiliasse os estados na proporção da receita per capita de cada um, de modo que os mais carentes fossem mais bem assistidos?. 
Bomfim, ao encerrar seu discurso, é vivamente aplaudido e cumprimentado pelos membros da Câmara favoráveis aos seus pareceres e as exposições no plenário estendem-se com o pronunciamento dos deputados Graccho Cardoso, Graciano Neves e Passos de Miranda no mesmo dia, finalizando com a exposição de Ferreira Braga no dia seguinte. Após isso, dá-se a apresentação dos pareceres sobre as emendas por parte da Comissão e, consequentemente, a votação. Contudo, as discussões referentes ao Projeto não se materializaram em reformas ou medidas para a difusão do ensino público. A redação final é apresentada no dia 24 de dezembro de 1907, aprovada em junho de 1908 e no dia 23 de novembro do mesmo ano, apresentada à Câmara pela Comissão de Instrução Pública. Passados dois anos, o Projeto é arquivado por ordem da Comissão de Finanças.

Embora as reformas nele previstas não tenham se concretizado, consideramos o Projeto uma rica fonte para os historiadores da educação que se debruçam sobre o contexto do Brasil República. Aos intérpretes da obra de Manoel Bomfim, em especial, o documento evidencia sua luta política pela democratização da instrução pública, tema tão recorrente em seus livros e discursos. Acreditamos, portanto, que não se pode preterir do estudo de sua breve experiência enquanto parlamentar e sua contribuição mais expressiva, qual seja, o debate em torno do Projeto Tavares Lyra.

\section{CONSIDERAÇÕES FINAIS}

Não tivemos com este texto a intenção de confrontar a participação de Manoel Bomfim nos debates em torno do Projeto Tavares Lyra com as exposições dos demais parlamentares envolvidos, o que seria um exercício possível. Detivemo-nos, antes, à investigação de seu posicionamento em relação ao papel do Estado no desenvolvimento e difusão da instrução primária por entendermos que a referida questão, como ele próprio mencionou, era capital no Projeto.

Outra possibilidade seria a pesquisa de seu posicionamento acerca da reforma do ensino secundário e superior. A despeito de não ter sido prioritária, este tema também é contemplado em sua exposição e pode se constituir objeto de estudo aos interessados. 
Concordamos que a intervenção da União na instrução primária gerou controvérsias que não se limitavam às implicações legais previstas na Constituição Federal de 1891. A Primeira República foi um período marcado pelo confronto entre a tradição e o novo modelo de sociedade que exigia transformações radicais na política, na economia e na educação. Tais mudanças, no entanto, não ocorreriam sem resistências.

O arquivamento do Projeto Tavares Lyra foi explicado, como mencionamos, pela falta de interesse das elites governantes no combate ao analfabetismo e pelo fato de a instrução popular não representar, naquele momento, uma necessidade ao país para os grupos hegemônicos no poder. Nesse sentido e em sintonia com a exposição de Bomfim, preferimos defender que a República, na medida em que restringiu o voto à população alfabetizada, criou uma necessidade e um dever público tendo em vista o precário cenário educacional brasileiro. Escolarizar as massas tornou-se tarefa fundamental e, por isso, a mobilização social em torno do problema.

Contudo, embora os incentivos do Estado pela disseminação da instrução primária não sejam prerrogativas da República, é com o veemente desenvolvimento da indústria nacional e o surgimento de novas demandas, quando a falta de mão de obra especializada passa a obstaculizar o desenvolvimento da economia e a segurança nacional se vê ameaçada pelo analfabetismo massivo é que a União intensifica seus investimentos na educação pública, fato que Manoel Bomfim e seus contemporâneos não puderam presenciar na primeira década do século XX.

Artigo recebido em: 15/01/2016 Aprovado para publicação em: 04/02/2016

MANOEL BOMFIM: PARLIAMENTARY DEBATES ON STATE AND PRIMARY EDUCATION IN THE FIRST DECADE OF THE TWENTIETH CENTURY

ABSTRACT: This study presents an investigation of the standpoint of the intellectual Manoel Bomfim (1868-1932) against the debate on the relation: State and primary education in parliamentary speeches delivered between the years of 1907 and 1908, currently available in the collection Documentos Parlamentares: Instrução Pública 
(Parliamentary Documents: Public Education), published in 1918 by the Jornal do Comércio (.Journal Trade). The position assumed by this author occurs in a context characterized by the attempts of free labor organization, structuring of the Republic, preparing the people for the exercise of citizenship and the coming of social demands that required investments in popular education. Manoel Bomfim shows to be committed to the development and dissemination of primary education and involved in intellectual and political movement in favor of the education of the working class.

KEYwoRDs: History of Education. State and primary education. First Republic. Manoel Bomfim.

\section{MANOEL BOMFIM: DEBATES PARLAMENTARES SOBRE ESTADO E INSTRUCCIÓN PRIMARIA EN LA PRIMERA DÉCADA DEL SIGLO XX}

RESUMEN: Este trabajo presenta una investigación a respecto del posicionamiento del intelectual Manoel Bomfim (1868-1932) frente al debate sobre la relación Estado e instrucción primaria en los discursos parlamentares proferidos entre los años de 1907 y 1908, actualmente disponibles en la colección Documentos Parlamentares: Instrucción Pública, publicada en 1918 por el Periódico del Comercio. La posición asumida por ese estudioso sobreviene en un contexto caracterizado por tentativas de organización del trabajo libre, estructuración de la República, preparo del pueblo para el ejercicio de ciudadanía y surgimiento de demandas sociales que exigieron gastos en la instrucción popular. Manoel Bomfim se muestra comprometido con el desarrollo y difusión de la instrucción primaria y, sumergido en el movimiento intelectual y político del período en favor de la escolarización de la clase trabajadora.

Palabras-clave: Historia de la Educación. Estado e instrucción primaria. Primera República. Manoel Bomfim.

\section{NOTAS}

1) Manoel Bomfim não pertencia à Comissão de Instrução e sua participação no debate restringiu-se à apreciação do Projeto, apresentação de emendas e votação. Os membros da Comissão de Instrução responsáveis pelo projeto foram: Teixeira Brandão como presidente e relator, Leão Velloso, José Bonifácio, Campos Cartiér, Antéro Botelho, Passos de Miranda e Affonso Costa.

2) “Incumbe, outrossim, ao Congresso, mas não privativamente: $1^{\circ}$ ) velar na guarda da Constituição e das leis e providenciar sobre as necessidades de caráter federal; $\left.2^{\circ}\right)$ animar no Pais o desenvolvimento das letras, artes e ciências, bem como a imi- 
gração, a agricultura, a indústria e comércio, sem privilégios que tolham a ação dos Governos locais; $3^{\circ}$ ) criar instituições de ensino superior e secundário nos Estados; $4^{\circ}$ ) prover a instrução secundária no Distrito Federal. (Artigo 35 da Constituição da República dos Estados Unidos do Brasil, promulgada em 24 de fevereiro de 1891. Disponível em: <http://www2.camara.leg.br/legin/fed/consti/1824-1899/constituicao-35081-24-fevereiro-1891-532699-publicacaooriginal-15017-pl.html>. Acesso em: 10 dez. 2015).

3) Sua exposição ocorreu no dia 5 de novembro de 1907 e está registrada entre as páginas 397 e 412 do documento analisado, qual seja, o Projeto Tavares Lyra, referenciado ao final deste texto.

4) Para apresentação dos dados biográficos de Manoel Bomfim, optamos pela fundamentação nos livros de Aguiar (2000) e Gontijo (2010), referenciados ao final deste artigo. Não citaremos os autores no decorrer de todo o trabalho para evitar repetições em excesso.

5) Para o desenvolvimento deste texto foram utilizadas reedições dos livros de Manoel Bomfim. As datas originais de publicação dos livros citados constam nas referências.

6) Cabe ressaltar que as discussões em torno da elaboração e discussão do Projeto Tavares Lyra tiveram início no dia 24 de junho de 1907, envolvendo toda a Câmara dos Deputados. As arguições do projeto foram feitas pelos deputados Castro Pinto, Arthur Orlando, Affonso Costa, Ferreira Braga, Augusto de Freitas, Serzedello Corrêa, Teixeira Brandão, José Bonifácio, Virgílio de Lemos, Pedro Moacyr, Manoel Bomfim, Graccho Cardoso, Graciano Neves, Passos de Miranda e Ferreira Braga. Contudo, o documento evidencia a presença de muitos parlamentares nas sessões. Para citar um exemplo, no dia 26 de setembro de 1907, Affonso Costa menciona a presença de 105 deputados na Câmara (BRASIL, 1918, p. 150). Os nomes citados durante as votações, além dos parlamentares já mencionados são: Victor do Amaral, Rodolpho Paixão, Julio de Mello, Galeão Carvalhal, Pandiá Colágeras, Carneiro de Rezende, James Darcy, José Lobo, Medeiros e Albuquerque, Elpídio de Mesquita, Germano Hasslocher, Dunshee de Abrantes, Esmeraldino Bandeira, Valois de Castro, Palmeira Rippier. Sr. Neiva e Sr. José Carlos. Manoel Bomfim se pronunciou apenas no dia 5 de novembro de 1907 e, posteriormente, participou das votações.

7) Optamos por atualizar a gramática original nas citações do Projeto Tavares Lyra.

8) Livro de Composição para o curso complementar das escolas primárias (1899); Livro de leitura: para o curso complementar das escolas primárias (1901); Revista O tico-tico (1905); Discurso O respeito à criança, pronunciado na Escola Normal (1906); Através do Brasil (1910); Lições de Pedagogia: teoria e prática da educação (1915); Noções de Psicologia (1917); Primeiras Saudades (1920); Pensar e dizer: estudo do símbolo no pen- 
samento e na linguagem (1923); O método dos testes: com aplicações à linguagem do ensino primário (1928).

9) É possível estabelecer relação entre as emendas de Manoel Bomfim e algumas políticas educacionais do Império. Com a Constituição Federal de 1824 ficou estabelecida a gratuidade do ensino primário a todos os cidadãos brasileiros Disponível em: <http://www.planalto.gov.br/ccivil_03/Constituicao/Constituicao24.htm>. Acesso em: 20 fev.2016. Em 1827 este princípio constitucional é regulamentado com a primeira Lei Geral de Ensino (Lei de 15 de outubro de 1827), que determinou a criação das "escolas de primeiras letras", o que possibilitou a difusão dessas escolas pelas províncias brasileiras. Disponível em: <http://www.planalto.gov.br/ccivil_03/ leis/LIM/LIM-15-10-1827.htm>. Acesso em: 20 fev. 2016). A partir de 1835, com o Decreto de Criação da Escola Normal (Lei n. 10, de 4 de abril de 1835) e a criação da primeira Escola Normal do Brasil em Niterói o acesso à escola primária foi ampliado e a criação dessas escolas foi intensificada. Embora as políticas educacionais imperiais não sejam comumente enfatizadas pelos intelectuais da Primeira República, cabe observar a permanência histórica do debate em torno da necessidade de difusão da instrução primária no país.

\section{REFERÊNCIAS}

AGUIAR, R. C. O rebelde esquecido: tempo, vida e obra de Manoel Bomfim. Rio de Janeiro: Topbooks, 2000.

ALVES FILHO, A. Manoel Bomfim: combate ao racismo, educação popular e democracia radical. 2. ed. São Paulo: Expressão Popular, 2013.

ANDRADE, Y. R. de. I(m)possível nação: o Brasil de Manoel Bom fim e de Paulo Prado no início do século XX. Dissertação (Mestrado em Ciências Sociais) - Pontifícia Universidade Católica de São Paulo (PUC-SP), São Paulo, 2008.

BILAC, O.; BOMFIM, M. Através do Brasil: prática da língua portuguesa: narrativa. São Paulo: Companhia das Letras, 2000. [original: 1910].

BOMFIM, M. BRASIL. Projeto Tavares Lyra. In: Documentos Parlamentares. Instrução Pública. Rio de Janeiro: Jornal do Comércio, 1918. p. 397-412.

. Lições de Pedagogia: teoria e prática da educação. 3. ed. Rio de Janeiro: Livraria Francisco Alves, 1926. [original: 1915].

. A América Latina, males de origem. Rio de Janeiro: Centro Edelstein de Pesquisas Sociais, 2008. [original: 1905].

. O Brasil Nação, realidade da soberania brasileira. 2. ed. Rio de Janeiro: Topbooks, 1996. [original: 1931]. 
O Brasil na América, caracterização da formação brasileira. 2. ed. Rio de Janeiro: Topbooks, 1997. [original: 1929].

O Brasil na História, deturpação das tradições, degradação política. 2. ed. Rio de Janeiro: Topbooks; Belo Horizonte: PUC-Minas, 2013. [original: 1930].

BOTELHO, A. Manoel Bomfim: um percurso da cidadania no Brasil. In: SCHWARCZ, L. M.; BOTELHO, A. (Org.). Um enigma chamado Brasil: 29 intérpretes e um país. São Paulo: Companhia das Letras, 2009. pp. 118-131.

BRASIL. Projeto Tavares Lyra. In: Documentos Parlamentares. Instrução Pública. Rio de Janeiro: Jornal do Comércio, 1918.

CARVALHO, J. M. de. A formação das almas: o imaginário da República no Brasil. São Paulo: Companhia das Letras, 1990.

CARVALHO, M. M. C. de. A escola e a República. São Paulo: Editora Brasiliense, 1989.

CHAVES, E. O. C. O liberalismo na política, economia e sociedade e suas implicações para a educação: uma defesa. In: LOMBARDI, J. C.; SANFELICE, J. L. (Org.). Liberalismo e educação em debate. Campinas/SP: Autores Associados; Histedbr, 2007. p. 1-60.

GONDRA, J. G. Artes de civilizar: medicina, higiene e educação escolar na Corte Imperial. Rio de Janeiro: EdUERJ, 2004.

GONTIJO, R. Manoel Bomfim. Recife: Fundação Joaquim Nabuco; Editora Massangana, 2010. (Coleção Educadores).

HERSCHMANN, M. M.; PEREIRA, C. A. M. A invenção do Brasil moderno: medicina, educação e engenharia nos anos 20 e 30. Rio de Janeiro: Editora Rocco, 1994.

LEITE, D. M. O caráter nacional brasileiro: história de uma ideologia. 4 ed. São Paulo: Pioneira, 1983.

MARX, K. Para a Crítica da Economia Política; Salário, Preço e Lucro; O rendimento e suas fontes: a economia vulgar. Tradução Edgard Malagodi et al. São Paulo: Abril Cultural, 1982.

NAGLE, J. Educação e Sociedade na Primeira República. São Paulo: EPU; Rio de Janeiro: Fundação Nacional de Material Escolar, 1974.

REIS, J. C. As identidades do Brasil: de Calmon a Bomfim. A favor do Brasil: direita ou esquerda? Rio de Janeiro: Editora FGV, 2006.

SILVA, J. M. de O. Da educação à revolução: radicalismo republicano em Manoel Bomfim. Dissertação (Mestrado em História Social) - Universidade de São Paulo (USP), São Paulo, 1990.

SOUTO MAIOR, L. Introdução ao pensamento de Manoel Bomfim: o discurso da modernidade no alvorecer do século XX. São Paulo: Centro de Publicação Popular do Instituto Mário Alves de Estudos Políticos, 1993. 
SOUZA, R. F. de. Lições da escola primária. In: SAVIANI, D. et al. O legado educacional do século XX no Brasil. Campinas: Autores Associados, 2004. p. 109-161.

VENTURA, R.; SUSSEKIND, F. História e Dependência: cultura e sociedade em Manoel Bomfim. São Paulo: Moderna, 1984.

Ligiane ApareCida da Silva: Pedagoga e mestre em Educação pela Universidade Estadual de Maringá. Doutoranda do Programa de Pós- Graduação da Universidade Estadual de Maringá. Desenvolve pesquisa na linha de história e historiografia da educação no Brasil, tendo priorizado o estudo de intelectuais e projetos educacionais da Primeira República. Pertence ao Grupo de Estudos e Pesquisas em História da Educação, Intelectuais e Instituições Escolares (GEPHEIINSE).

E-mail: ligi.ped@gmail.com

Maria Cristina Gomes MACHado: Doutora em Filosofia e História da Educação pela Universidade Estadual de Campinas (Unicamp). Professora associada da Universidade Estadual de Maringá (UEM) onde atua no Programa de Pós-Graduação em Educação (Mestrado e Doutorado). Atua na área da educação com ênfase em Fundamentos da Educação. Entre outros tópicos, estuda: História da Educação, Intelectuais, Instituições Escolares, Fontes e Fundamentos, Educação Pública.

E-mail: mcsm.uem@gmail.com 